\title{
PENGENDALIAN EMISI GAS BUANG BOILER BATUBARA DENGAN SISTEM ABSORBSI
}

\author{
Silvy Djayanti, Purwanto, Setia Budi Sasongko \\ Departemen Perindustrian \\ Balai Besar Teknologi Pencegahan Pencemaran Industri \\ Jl. Ki Mangun Sarkoro 6, Semarang \\ e-mail:silvy_bbtppi@yahoo.com
}

\begin{abstract}
Absorption study of emission gas $\left(\mathrm{SO}_{2}, \mathrm{NO}_{2}, \mathrm{CO}\right.$, and $\mathrm{CO}_{2}$ ) from coal boiler with $\mathrm{NaOH}$ absorber waste of textile industry has been done. Acid gasses neutralized and particulate trapped by $\mathrm{NaOH}$ solution. $\mathrm{NaOH}$ was chosen for efficiency of waste neutralized and obtained from waste absorber and conventional textile finishing process $(\mathrm{NaOH})$ with the concentration of $100 \mathrm{~mol} / \mathrm{m}^{3}$. Emitted disposal gas concentration at flow rate 500, 1000, 2500, 5000, and 10,000 L/hour before and after absorption was measured and analyzed using MATLAB and EXCEL software. There was no significant difference between observation and theoretical calculation data $(P<0,05)$. At flow rate 2500 L/hour concentration of emission gas have shown under threshold values. A liquid-gas absorption model that obtained form this study could be used to predict optimum flow rate required for reducing the emission gas concentration to the quality threshold values.
\end{abstract}

Keywords: Gas absorber, boiler disposal gas emission, NaOH textile waste, Liquid-gas Absorption Mode

\section{PENDAHULUAN}

Pencemaran udara yang dihasilkan dari emisi boiler berbahan bakar batubara memberikan kontribusi yang besar bagi pencemaran lingkungan. Data yang diperoleh dari boiler batubara di unit utilitas pada bulan Juli 2006 di Industri tekstil di kota Pekalongan, menunjukkan konsentrasi $\mathrm{SO}_{2}, \mathrm{NO}_{2}, \mathrm{CO}$, dan $\mathrm{CO}_{2}$ masih tinggi. Bahkan $\mathrm{SO}_{2}$ mencapai $1144,16 \mathrm{mg} / \mathrm{m}^{3}$ yang berarti di atas baku mutu sumber tidak bergerak untuk utilitas dan boiler, menurut Surat Keputusan Gubernur Jateng No. 10 tahun 2000. Sementara itu untuk parameter $\mathrm{NO}_{2} \quad 125,60 \mathrm{mg} / \mathrm{m}^{3}, \quad \mathrm{CO} \quad 6,514$ $\mathrm{mg} / \mathrm{m}^{3}$, dan $\mathrm{CO}_{2} 6,73$. $^{1}$

Hal ini berbeda jauh kondisinya dengan boiler dengan bahan bakar minyak yang konsentrasi gas buangnya jauh lebih kecil daripada boiler dengan bahan bakar batubara. Data konsentrasi emisi dari boiler berbahan bakar solar jauh di bawah nilai ambang yaitu
$\mathrm{SO}_{2}$ maksimal $81,145 \quad \mathrm{mg} / \mathrm{m}^{3}, \quad \mathrm{NO}_{2}$ $55,50 \mathrm{mg} / \mathrm{m}^{3}, \mathrm{CO} \quad 0,115 \mathrm{mg} / \mathrm{m}^{3} \quad \mathrm{CO}_{2} \quad 0,070$ $\mathrm{mg} / \mathrm{m}^{3}$, dan partikulat $27,255 \mathrm{mg} / \mathrm{m}^{3}$.

Data emisi tahun 2006 menunjukkan kenaikan konsentrasi gas emisi cerobong pada tahun sebelumnya yaitu tahun 2005, konsentrasi $\mathrm{SO}_{2} \quad 967,26 \mathrm{mg} / \mathrm{m}^{3}, \mathrm{NO}_{2} \quad 113,56$ $\mathrm{mg} / \mathrm{m}^{3}, \quad$ CO $25,8 \mathrm{mg} / \mathrm{m}^{3}$. Peningkatan emisi boiler berbahan bakar batubara diprediksikan di tahun mendatang akan lebih mengalami peningkatan ditambah dengan usia boiler yang sudah semakin tua dan pemakaian bahan bakar batubara yang dipakai karena pertimbangan ekonomis. Hal ini perlu diimbangi dengan instalasi penanggulangan pencemaran dan perawatan alat yang kontinyu.

Perumusan masalah yang muncul dari studi kasus di pabrik tekstil di Pekalongan yaitu boiler dengan sistem pembakaran fluidized bed dengan kapasitas produksi 10 ton/ jam yang telah diserap oleh absorber menghasilkan emisi 
gas yang belum sesuai dengan Keputusan Gubernur No. 10 Tahun 2000, yaitu melebihi baku mutu emisi sumber tidak bergerak. Efisiensi proses penyerapan antara fase cair pada absorber dan fase gas buang dari boiler adalah faktor yang perlu diperhatikan dalam pengendalian emisi gas buang boiler batubara sistem absorbsi. Gas buang emisi $\mathrm{SO}_{1}, \mathrm{NO}_{2}$, $\mathrm{CO}$, dan $\mathrm{CO}_{2}$ harus diminimasi untuk mengendalikan dampak pencemaran akibat emisi yang dihasilkan.

Hipotesa yang muncul yaitu laju alir absorban akan meningkatkan penyerapan gas emisi boiler ( $\mathrm{SO}_{2}, \mathrm{NO}_{2}, \mathrm{CO}, \mathrm{CO}_{2}$ ) yang berakibat menurunnya konsentrasi gas emisi boiler yang dibuang ke udara. Pemilihan penyerap gas emisi yang bersifat asam, lebih efisien menggunakan absorben yang bersifat basa.

Dari perumusan masalah, dihasilkan tujuan penelitian yaitu untuk menganalisis emisi gas buang boiler batubara, memenuhi baku mutu yang dipersyaratkan atau tidak. Selain itu juga menganalisis agar penyerapan bisa dijadikan sebagai sebuah model dalam mengendalikan konsentrasi gas buang emisi, dan melakukan simulasi optimasi laju alir $\mathrm{NaOH}$ yang optimal sehingga gas buang emisi memenuhi baku mutu yang dipersyaratkan. Diharapkan penelitian ini dapat memberi manfaat dan informasi ilmiah mengenai kondisi yang ada sebagai dasar masukan kepada pihak industri dalam meningkatkan efisiensi penyerapan gas emisi. Memberikan solusi efisiensi penyerapan emisi gas dengan menentukan laju alir absorber yang tepat. Menginformasikan dan membantu memberikan rasa aman bagi masyarakat di sekitar lokasi pabrik bahwa gas buang emisi khususnya $\mathrm{SO}_{2}$, $\mathrm{NO}_{2}, \mathrm{CO}$, dan $\mathrm{CO}_{2}$ dapat diminimasi sehingga dampak pencemaran dapat ditekan seminimal mungkin.

\section{METODA PENELITIAN}

Pengamatan penelitian meliputi emisi boiler batubara, pencatatan dan analisa laboratorium emisi gas buang sebelum dan sesudah absorber, pencatatan laju alir gas dan penyerap, pencatatan spesifikasi dan dimensi absorber gas, evaluasi proses absorbsi, perhitungan efisiensi penyerapan cair-gas, dan perhitungan konsentrasi gas keluar absorber gas.

Penelitian dimulai dari pengambilan emisi gas buang boiler yang telah diserap di absorber dengan mengubah laju alir cairan $\mathrm{NaOH}$. Pengambilan sampel gas $\mathrm{SO}_{2}, \mathrm{NO}_{2}, \mathrm{CO}$, dan $\mathrm{CO}_{2}$ sebelum dan sesudah absorber dengan kantong udara (bag air sampler) pada saat boiler dan absorber sedang beroperasi. Pengambilan sampel gas sebelum masuk absorber diambil pada lubang saluran output boiler-input absorber dan output absorber diambil pada sampling hole cerobong. Kondisi ini divariasi dengan laju alir larutan $\mathrm{NaOH}$ yang berasal dari limbah cair proses pembuatan tekstil. Untuk menganalisa sampel emisi digunakan gas analizer.

Pengolahan data dihitung menggunakan program Matlab dan excel, dengan menyusun neraca komponen dan menghitung Kga (koefisien transfer massa gas-cair) untuk mendapatkan jumlah gas emisi $\mathrm{SO}_{2}, \mathrm{NO}_{2}, \mathrm{CO}$, dan $\mathrm{CO}_{2}$ yang terserap sehingga bisa diketahui gas buang yang diemisikan absorber.

Variabel penelitian meliputi variabel tetap dan variabel berubah. Variabel tetap adalah konsentrasi larutan $\mathrm{NaOH}$, laju alir gas masuk absorber, konsentrasi gas masuk absorber, temperatur gas masuk, dimensi absorber, dan waktu pengambilan sampel. Sedangkan variabel berubah adalah laju alir cairan penyerap $(\mathrm{NaOH})$. 
Teknik analisis data sebagai hasil akhir membuat kurva hubungan konsentrasi gas emisi boiler batubara vs laju alir absorber. Menganalisis perbedaan hasil percobaan dan perhitungan dari kurva kemudian mencari titik optimasi laju air terhadap baku mutu emisi.

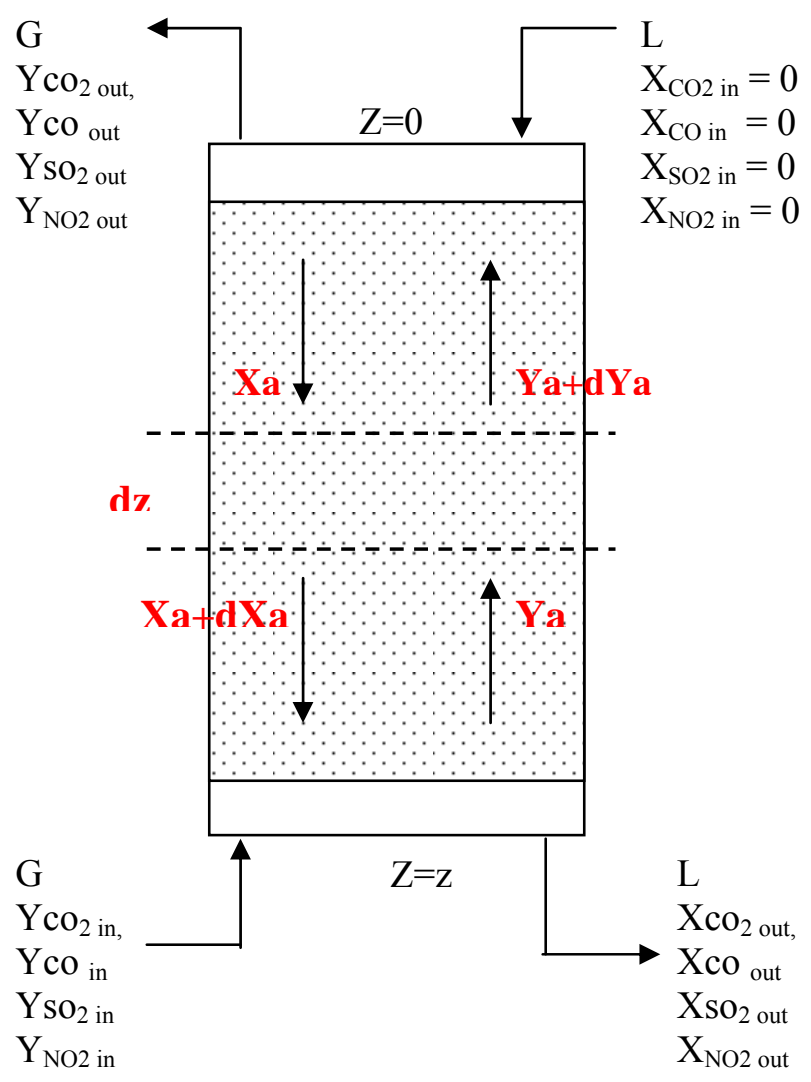

Gambar 2. Penampang absorber gas.

Keterangan :

$$
\begin{aligned}
\mathrm{a}= & \text { area mass transfer per unit } \\
& \text { volume, } \mathrm{ft}^{2} / \mathrm{ft}^{3} \\
\mathrm{G}= & \text { laju alir gas inert, mol/jam } \\
\mathrm{K}_{\mathrm{g}}= & \text { konstanta transfer massa, } \\
& \text { mol/jam }\left(\mathrm{ft}^{2}\right) \\
\mathrm{L} & =\text { laju alir cairan inert, mol/jam } \\
\mathrm{H}= & \text { konstanta henry } \\
\mathrm{S}= & \text { tower cross section, } \mathrm{ft}^{2} \\
\mathrm{X}= & \text { mol fraksi komponen dalam } \\
& \text { fase cair, mol/mol cairan inert } \\
\mathrm{Y}= & \text { mol fraksi komponen dalam } \\
& \text { fase cair, mol/mol gas inert } \\
\mathrm{Z}= & \text { tinggi absorber, } \mathrm{ft}
\end{aligned}
$$

Pada Gambar 2 bisa ditampilkan gas masuk ( $G_{\text {in }}$ ) pada bagian bawah absorber, berlawanan arah dengan cairan $\mathrm{NaOH}$ penyerap dari atas absorber $\left(\mathrm{L}_{\mathrm{in}}\right)$. Gas dihisap dengan pompa vakum di bagian atas absorber melewati packing ( $\mathrm{dz}$ ) lalu keluar dari outlet atas absorber ( $\mathrm{G}_{\text {out }}$ ). Reaksi kimia dalam absorber terjadi pada packing absorber, dimana cairan $\mathrm{NaOH}$ yang membasahi packing mengalami kontak langsung dengan gas yang melewatinya. Cairan $\mathrm{NaOH}$ yang telah kontak dengan gas emisi akan keluar pada bagian bawah absorber ( $\mathrm{L}_{\text {out }}$ ).

Penjelasan proses absorbsi gas-cair melalui lapisan film akan dijelaskan pada persamaan 5-22.

$$
\begin{aligned}
& \text { Input }=L X_{A}+G Y_{A} \\
& \text { Output }={ }_{L}\left(X_{A}+\frac{d\left(X_{A}\right)}{d z} d z\right)+G\left[Y_{A}+\frac{d Y_{A}}{d z} d z\right]+k S H o X_{A} X_{B} d z(6)
\end{aligned}
$$

Asumsi keadaan steady state

Accumulation $=0$

$$
\begin{gathered}
\text { Input }- \text { output }=\text { accumulation } \\
L X_{A}+G Y_{A}-\left[L\left(X_{A}+\frac{d\left(X_{A}\right)}{d z} d z\right)+G\left[Y_{A}+\frac{d Y_{A}}{d z}\right]+k S H o X_{A} X_{B} d z\right]=0 \\
-L \frac{d\left(X_{A}\right)}{d z}-G \frac{d Y_{A}}{d z}-k S H o X_{A} X_{B}=0
\end{gathered}
$$

Sehingga yang dipertimbangkan fase gasnya saja. Neraca massa untuk komponen A :

$$
\begin{aligned}
& \text { Input }=G Y_{A} \\
& \text { Output }=G\left[Y_{A}+\frac{d Y_{A}}{d z} d z\right]-K_{G a} S\left(Y_{A}-Y_{A}^{*}\right) d z
\end{aligned}
$$

Accummulation $=0$

Kemudian neraca massa fase gas adalah :

$$
\begin{gathered}
\text { Input }- \text { output }=\text { accumulation } \\
G Y_{A}-\left[G\left[Y_{A}+\frac{d Y_{A}}{d z} d z\right]+K_{G a} S\left(Y_{A}-Y_{A}^{*}\right) d z\right]=0
\end{gathered}
$$




$$
\begin{gathered}
G \frac{d Y_{A}}{d z}-K_{G a} S\left(Y_{A}-Y_{A}^{*}\right)=0 \\
Y_{A}^{*}=H X_{A} \\
G \frac{d Y_{A}}{d z}-K_{G a} S\left(Y_{A}-H X_{A}\right)=0
\end{gathered}
$$

subtitusikan persamaan (4.4) ke persamaan (4.9) maka didapat

$$
L \frac{d\left(X_{A}\right)}{d z}-K_{G a} S\left(Y_{A}-H X_{A}\right)+k S H o X_{A} X_{B}=0
$$

dengan pendekatan yang sama maka didapatkan

$$
\begin{aligned}
& G \frac{d Y_{\mathrm{CO} 2}}{d z}-K_{G} a S\left(Y_{\mathrm{CO} 2}-H X_{\mathrm{CO} 2}\right)=0 \\
& G \frac{d Y_{C O}}{d z}-K_{G} a S\left(Y_{C O}-H X_{C O}\right)=0 \\
& G \frac{d Y_{\mathrm{SO} 2}}{d z}-K_{G} a S\left(Y_{\mathrm{SO}_{2}}-H X_{\mathrm{SO}_{2}}\right)=0 \\
& G \frac{d Y_{\mathrm{NO} 2}}{d z}-K_{G} a S\left(Y_{\mathrm{NO} 2}-H X_{\mathrm{NO}_{2}}\right)=0 \\
& L \frac{d\left(X_{\mathrm{CO} 2}\right)}{d z}-K_{G} a S\left(Y_{\mathrm{CO} 2}-H_{\mathrm{CO} 2}\right)+k_{1} \mathrm{SHo}^{3} X_{\mathrm{CO}_{2}} X^{2}{ }_{\mathrm{NaOH}}=0 \\
& L \frac{d\left(X_{\mathrm{SO}_{2}}\right)}{d z}-K_{G} a S\left(Y_{\mathrm{SO} 2}-\mathrm{HX}_{\mathrm{SO} 2}\right)+k_{2} \mathrm{SHo}^{3} X_{\mathrm{SO} 2} X_{\mathrm{NaOH}}^{2}=0 \\
& L \frac{d\left(X_{\mathrm{NO} 2}\right)}{d z}-K_{G} a S\left(Y_{\mathrm{NO} 2}-H X_{\mathrm{NO} 2}\right)+k_{3} S \mathrm{H}^{2} X_{\mathrm{NO} 2} X_{\mathrm{NaOH}}=0
\end{aligned}
$$

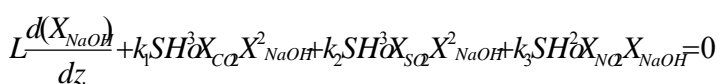

Dengan boundary condition

$$
\begin{aligned}
\mathrm{Z}=0 \rightarrow & \mathrm{Y}_{\mathrm{CO} 2}=\mathrm{Y}_{\mathrm{CO} 2 \text { out }} ; \mathrm{Y}_{\mathrm{CO}}=\mathrm{Y}_{\mathrm{CO} \text { out }} ; \mathrm{Y}_{\mathrm{SO} 2}= \\
& \mathrm{Y}_{\mathrm{SO} 2 \text { out }} ; \mathrm{Y}_{\mathrm{NO} 2}=\mathrm{Y}_{\mathrm{NO} 2 \text { out }} ; \mathrm{X}_{\mathrm{CO} 2}=0 ; \\
& \mathrm{X}_{\mathrm{CO}}=0 ; \mathrm{X}_{\mathrm{SO} 2}=0 ; \mathrm{X}_{\mathrm{NO} 2}=0 ; \mathrm{X}_{\mathrm{NaOH}}= \\
& \mathrm{X}_{\mathrm{NaOHin}} \\
\mathrm{Z}=\mathrm{Z} \longrightarrow & \mathrm{Y}_{\mathrm{CO} 2}=\mathrm{Y}_{\mathrm{CO} 2 \text { in }} ; \mathrm{Y}_{\mathrm{CO}}=\mathrm{Y}_{\mathrm{CO} \text { in }} ; \mathrm{Y}_{\mathrm{SO} 2}= \\
& \mathrm{Y}_{\mathrm{SO} 2 \text { in }} ; \mathrm{Y}_{\mathrm{NO} 2}=\mathrm{Y}_{\mathrm{NO} 2 \text { in }} ; \mathrm{X}_{\mathrm{CO} 2}=\mathrm{X}_{\mathrm{CO} 2 \text { out }} \\
& ; \mathrm{X}_{\mathrm{CO}}=\mathrm{X}_{\mathrm{CO} \text { out }} ; \mathrm{X}_{\mathrm{SO} 2}=\mathrm{X}_{\mathrm{SO} 2 \text { out }} ; \mathrm{X}_{\mathrm{NO} 2}= \\
& \mathrm{X}_{\mathrm{NO} 2 \text { out }} ; \mathrm{X}_{\mathrm{NaOH}}=\mathrm{X}_{\mathrm{NaOHo}}
\end{aligned}
$$

\section{HASIL PERCOBAAN \\ DAN

\begin{tabular}{|c|c|c|c|c|c|c|c|}
\hline \multirow[t]{3}{*}{ Gas } & \multirow{3}{*}{$\begin{array}{l}\text { Gas emisi } \\
\text { Sebelum } \\
\text { Absorber }\end{array}$} & \multicolumn{5}{|c|}{$\begin{array}{c}\text { Konsentrasi }\left(\mathrm{mg} / \mathrm{m}^{3}\right) \text { gas emisi setelah } \\
\text { Absorber pada laju alir }\end{array}$} & \multirow{3}{*}{\begin{tabular}{|c} 
Baku \\
Mutu \\
$(\mathrm{mg}$ \\
$\left.\mathrm{m}^{3}\right)$
\end{tabular}} \\
\hline & & & 1000 & 2500 & 5000 & $100001 /$ & \\
\hline & & $500 \mathrm{l} / \mathrm{jam}$ & $1 / \mathrm{jam}$ & 1/jam & 1/jam & jam & \\
\hline $\mathrm{SO}_{2}$ & 1512.76 & 1144.16 & 1034.97 & 665.34 & 563.72 & 501.81 & 800 \\
\hline $\mathrm{NO}$ & 324.275 & 125.608 & 114.16 & 106.27 & 87.682 & $\mid 67.029$ & 1000 \\
\hline $\mathrm{CO}$ & 8.5542 & 6.5143 & 5.8286 & 5.4857 & 3.7714 & 2.4000 & - \\
\hline $\mathrm{CO}_{2}$ & 125611.5 & 121112.5 & 112654.4 & 100237.2 & 74143.1 & 57766.8 & - \\
\hline
\end{tabular} \\ PEMBAHASAN}

Dengan melihat material yang akan dikontakkan ke dalam absorber yaitu gas asam dan cairan penyerap basa, maka proses ini termasuk dalam absorbsi kimia, di mana gas terlarut dalam larutan penyerap disertai dengan adanya reaksi kimia. Absorbsi kimia mempengaruhi peningkatan koefisien perpindahan massa (KgA) disebabkan oleh makin besarnya luas efektif antar muka.

Dari identifikasi lapangan didapatkan data bahwa pada proses pembakaran di unit utilitas menghasilkan limbah konsentrasi tinggi yang dapat mencemari lingkungan. Jenis parameter yang diamati pada penzelitian ini adalah $\mathrm{SO}_{2}, \mathrm{NO}_{2}, \mathrm{CO}, \mathrm{CO}_{2}$ seperti pada Tabel 1.

Tabel 1. Emisi gas buang sebelum dan sesudah absorber dalam satuan $\mathbf{m g} / \mathrm{m}^{3}$ 
Gambar 3, 4, 5, dan 6 perbandingan hasil teoritis dan praktis dengan menggunakan program matlab dan excel Gambar

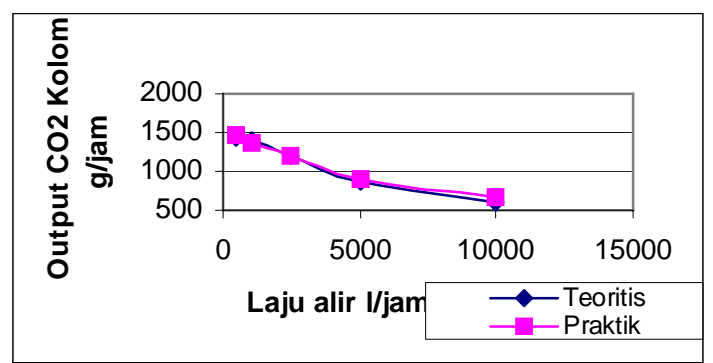

Gambar 3. Grafik perbandingan hasil teoritis dan hasil lapangan $\mathrm{CO}_{2}$

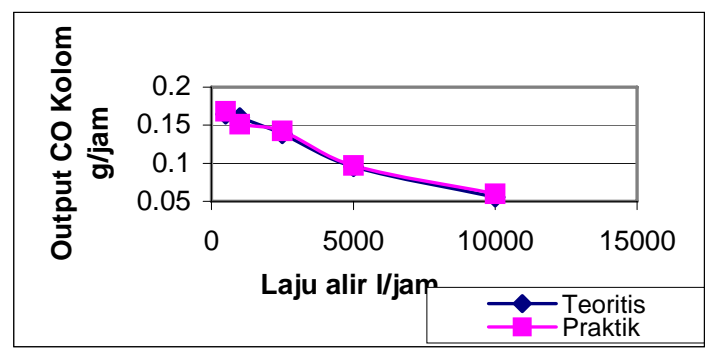

Gambar 4. Grafik perbandingan hasil teoritis dan hasil lapangan $\mathrm{CO}$

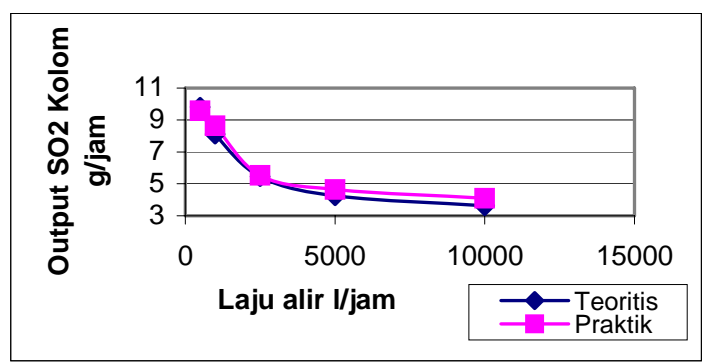

Gambar 5. Grafik perbandingan hasil teoritis dan hasil lapangan SO2

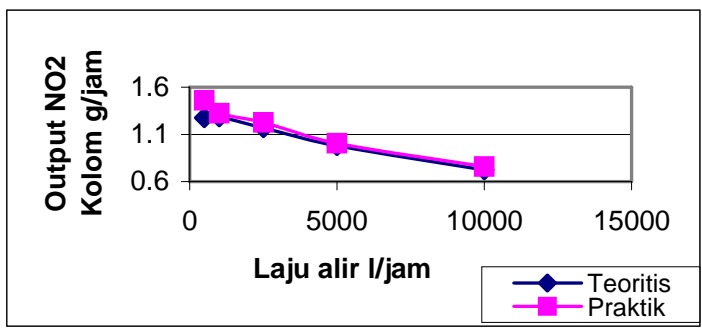

Gambar 6. Grafik perbandingan hasil teoritis dan hasil lapangan $\mathrm{NO}_{2}$
Dari Tabel 1. nampak bahwa semakin tinggi laju alir penyerap maka makin rendah konsentrasi gas buang yang keluar cerobong. Hasil tabel telah dikonversi menjadi $\mathrm{mg} / \mathrm{m}^{3}$. Hasil percobaan penelitian di unit boiler untuk parameter $\mathrm{SO}_{2}$ menunjukkan hasil yang melebihi baku mutu emisi sumber tidak bergerak sebesar $800 \mathrm{mg} / \mathrm{m}^{3}$. Hasil percobaan yang melebihi tersebut pada laju alir $500 \&$ 1000 L/jam. Pada laju alir 2500 - 10000 L/jam, konsentrasi $\mathrm{SO}_{2}$ dipastikan sudah di bawah baku mutu emisi yang disyaratkan menurut Keputusan Gubernur Jawa Tengah No 10 Tahun 2000. Untuk parameter $\mathrm{NO}_{2}, \mathrm{CO}$, dan $\mathrm{CO}_{2}$ pada laju alir $500 \mathrm{~L} / \mathrm{jam}$ sudah memenuhi baku mutu. Pada parameter $\mathrm{CO}$ dan $\mathrm{CO}_{2}$ tidak ada baku mutunya. Penelitian $\mathrm{CO}$ dan $\mathrm{CO}_{2}$ hanya untuk mengetahui besaran konsentrasi gas yang dibuang dan dampak terhadap masyarakat dan efek rumah kaca.

Data dihitung dengan menyusun neraca komponen dan menghitung parameterparameter absorbsi gas $\mathrm{SO}_{2}, \mathrm{NO}_{2}, \mathrm{CO}$, dan $\mathrm{CO}_{2}$ sehingga simulasi pemodelan matematika dapat dilakukan untuk mengetahui gas buang yang diemisikan absorber. Parameter-perameter tersebut adalah Kga (koefisien perpindahan massa) dan $\mathrm{H}$ (konstanta Henry), yang dihitung melalui suatu pemodelan matematika dengan memvariasi konsentrasi gas di fase gas dan cair.

Perhitungan dilakukan secara simultan menggunakan suatu pemrogaman MATLAB untuk memperoleh harga koefisien perpindahan massa overall dan konstanta Henry. Urutan pemrograman dengan cara memasukkan model matematika dengan memasukkan kondisi batas (Boundary Condition) dari operasi absorbsi.Tebakan awal harga konstanta dimasukkan kemudian dilakukan simulasi kemudian hasil simulasi dicocokkan dengan batasan yang ada. Jika sudah cocok maka tebakan sudah benar, jika belum maka langkah 
13 sampai 6 diulangi langkah-langkah di atas diulangi untuk variabel flow rate yang lain, lalu dibuat rumus empiris dari kosntanta-kosntanta dengan variabel bebas laju alir penyerap dilakukan simulasi ulang untuk mencari flow rate minimum.

Pada Gambar 3, 4, 5, dan 6 dapat dilihat bahwa penelitian dan hasil perhitungan perilaku penyerapan semakin besar dengan penambahan laju alir cairan $\mathrm{NaOH}$ penyerap yang diambil dari IPAL industri tekstil. Gas emisi telah memenuhi baku mutu emisi pada laju alir 2500 L/ jam. Hal ini disebabkan oleh harga Kga yang semakin besar berbanding lurus dengan laju alir. Harga Kga ditentukan oleh persamaan absorbsi fisik antara gas buang boiler dengan limbah $\mathrm{NaOH}$. Molekul gas dalam keadaan tetap akan berdifusi dari tubuh gas ke

permukaan batas gas cair. Fase selanjutnya adalah penyerapan dengan rekasi kimia untuk meningkatkan laju penyerapan dan menambah jumlah zat terlarut setelah penyerapan fisika.

Dari hasil perbandingan antara perhitungan/ simulasi dan percobaan didapatkan hasil perhitungan mendekati hasil penelitan, dengan persen kesalahan total 5\%. Emisi yang dihasilkan pada perhitungan hasil penelitian lebih kecil daripada emisi hasil percobaan. Hal ini karena kondisi emisi hasil percobaan sangat fluktuatif dan banyak faktor saat percobaan sangat mempengaruhi, seperti tersumbatnya spray pada absorber. Optimasi laju alir yang didapat dari perhitungan adalah $2500 \mathrm{~L} / \mathrm{jam}$. Pada laju alir tersebut gas emisi $\mathrm{SO}_{2}$ sudah di bawah baku mutu. Kondisi ini harus di jadikan sebagai acuan karena jika melebihi laju alir tersebut akan berdampak pada kinerja pompa dan daya listrik yang dibutuhkan, sehingga akan menimbulkan pemborosan energi.

Perhitungan neraca massa penyerapan didapatkan hasil gas yang terserap dalam satuan mol/jam, seperti Tabel 2.

\section{Tabel 2. Emisi gas terserap absorber}

\begin{tabular}{|c|c|c|c|c|c|}
\hline \multirow[t]{3}{*}{$\begin{array}{c}\text { Gas } \\
\text { Emisi }\end{array}$} & \multicolumn{5}{|c|}{$\begin{array}{c}\text { Konsentrasi Gas emisi yang terserap ( mol/jam ) } \\
\text { setelah absorber pada laju alir }\end{array}$} \\
\hline & 500 & 1000 & 2500 & & \\
\hline & 1/jam & 1/jam & 1/jam & $5000 \mathrm{l} / \mathrm{jam}$ & 100001/jam \\
\hline $\mathrm{CO}_{2}$ & 2.039 & 4.471 & 8.005 & 15.308 & 19.924 \\
\hline $\mathrm{CO}$ & 0.002 & 0.002 & 0.002 & 0.003 & 0.004 \\
\hline $\mathrm{SO}_{2}$ & 0.053 & 0.067 & 0.116 & 0.130 & 0.138 \\
\hline $\mathrm{NO}_{2}$ & 0.052 & 0.055 & 0.057 & 0.062 & 0.067 \\
\hline
\end{tabular}

Dari tabel 2. Gas yang terserap oleh limbah tekstil menunjukkan peningkatan pada laju alir absorben yang semakin besar. Penyerapan $\mathrm{CO}_{2}$ terhadap limbah $\mathrm{NaOH}$ sangat besar. Ini ditunjukkan dari $\mathrm{CO}_{2}$ yang sangat reaktif mengikat dan bereaksi dengan $\mathrm{NaOH}$. Penyerapan pada parameter $\mathrm{NO}_{2}, \mathrm{CO}$, dan $\mathrm{SO}_{2}$ juga meningkat tetapi cenderung kecil. Absorbsi gas yang terserap sangat tergantung pada suhu. Semakin tinggi suhu yang keluar dari boiler, semakin besar gas yang terserap. Bahan absorben $\mathrm{NaOH}$ dengan konsentrasi yang besar juga menambah tinggi gas yang terserap. Peningkatan laju alir $\mathrm{NaOH}$ meningkatkan harga koefisien transfer massa gas - cair $\left(\mathrm{K}_{\mathrm{G}} \mathrm{a}\right)$, karena peningkatan laju alir $\mathrm{NaOH}$ akan menyebabkan kontak permukaan antara fase gas dan fase cair akan semakin baik. Larutan $\mathrm{NaOH}$ yang sudah banyak mengikat dan bereaksi dengan gas emisi akan segera digantikan dengan larutan penyerap yang baru. Hal ini akan menyebabkan jumlah gas emisi yang ditransfer dari fase gas ke fase cair per satuan waktu akan semakin banyak pula.

Perhitungan persamaan matematis dan dihitung dengan menggunakan program MATLAB, dihasilkan nilai Kga tiap laju alir, seperti pada Tabel.3. 
Tabel 3. Koefisien transfer massa

\begin{tabular}{|c|c|c|c|c|}
\hline \multirow{2}{*}{$\begin{array}{c}\text { Laju alir } \\
\mathrm{NaOH}\end{array}$} & \multicolumn{4}{|c|}{$\mathrm{K}_{\mathrm{G}} \mathrm{a}$ mol/jam.ft } \\
\cline { 2 - 5 } & $\mathrm{SO}_{2}$ & $\mathrm{NO}_{2}$ & $\mathrm{CO}$ & $\mathrm{CO}_{2}$ \\
\hline 500 & 86.169 & 277.340 & 86.911 & 16.905 \\
\hline 1000 & 115.720 & 305.680 & 117.510 & 38.472 \\
\hline 2500 & 242.930 & 327.330 & 134.120 & 73.048 \\
\hline 5000 & 292.670 & 384.090 & 244.170 & 161.350 \\
\hline 10000 & 328.820 & 463.880 & 381.650 & 235.640 \\
\hline
\end{tabular}

Dari Tabel 3. Koefisien transfer massa (Kga) menunjukkan peningkatan dengan bertambahnya laju alir cairan absorben. Hal ini disebabkan absorben yang kontak dengan gas emisi semakin besar, dan penyerapan cairan kimia terhadap gas emisi makin besar. Untuk menentukan harga Kga didasarkan pada waktu tertentu pada saat perpindahan massa berlangsung. Besarnya harga Kga tergantung dari tekanan, suhu emisi dan suhu absorben di dalam proses penyerapan gas.

Perhitungan mencari harga Kga dilakukan secara simultan dengan memasukkan harga mol gas dibagi mol gas inert (harga y) sebagai batas atas dan batas bawah. Dari perhitungan ini didapatkan pula konstanta Henry $(\mathrm{H})$ sebesar 0,122 berdasarkan tebakan awal kondisi atas dan bawah konsentrasi gas emisi keluar cerobong dalam bentuk fraksi mol. Secara keseluruhan nilai konstanta Henry tidak ada perubahan terhadap laju alir.

\section{KESIMPULAN}

Perilaku penyerapan gas emisi semakin besar dengan penambahan laju alir cairan penyerap yang diambil dari IPAL industri tekstil. Gas emisi telah memenuhi baku mutu emisi pada laju alir $2500 \mathrm{~L} /$ jam. Hal ini disebabkan kelarutan gas emisi yang bersifat asam akan cepat larut dengan penyerap basa. Pada harga Kga yang semakin besar berbanding lurus dengan laju alir.

Optimasi laju alir yang didapat dari perhitungan adalah $2500 \mathrm{~L} / \mathrm{jam}$. Pada laju alir tersebut gas emisi $\mathrm{SO}_{2}$ sudah di bawah baku mutu. Kondisi ini harus dijadikan sebagai acuan karena jika melebihi laju alir tersebut akan berdampak pada kinerja pompa dan daya listrik yang dibutuhkan, sehingga akan menimbulkan pemborosan energi.

\section{DAFTAR PUSTAKA}

Dutatex. PT. 2006, Hasil Pemeriksaan Kualitas Udara Emisi

2

Faltatex. PT. 2006, Hasil Pemeriksaan Kualitas Udara Emisi

3 Howard E. Hesketh. 1996, Air Pollution Control : Traditional and Hazardous Pollutants, Southern Illinois University.

Levenspiel. Octave 1972. , Chemical Reaction Engineering, John Wiley \& Sons Inc, New York.

5 Purwanto. 2005, Permodelan Rekayasa Proses dan Lingkungan, Badan Penerbit Universitas Diponegoro Semarang.

6 Perry R, Chemical Engineering Handbook, Fifth Edition, Mc. Graw Hill, Kogakusha, Ltd.

1973 
